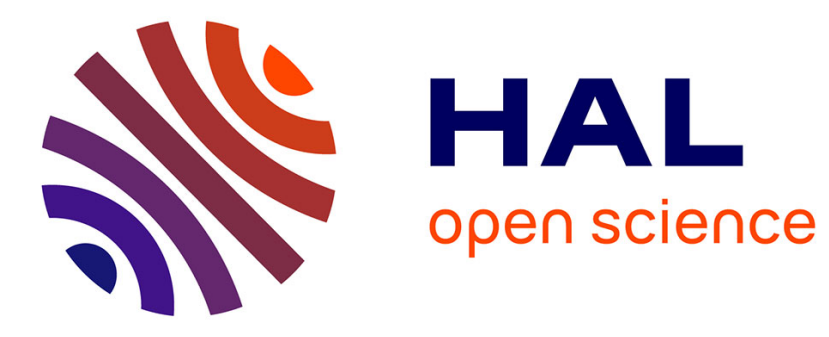

\title{
Fluorophosphate glasses containing manganese
}

\author{
T. Djouama, A. Boutarfaia, M. Poulain
}

\section{To cite this version:}

T. Djouama, A. Boutarfaia, M. Poulain. Fluorophosphate glasses containing manganese. Journal of Physics and Chemistry of Solids, 2010, 69 (11), pp.2756. 10.1016/j.jpcs.2008.07.004 . hal-00614334

\section{HAL Id: hal-00614334 \\ https://hal.science/hal-00614334}

Submitted on 11 Aug 2011

HAL is a multi-disciplinary open access archive for the deposit and dissemination of scientific research documents, whether they are published or not. The documents may come from teaching and research institutions in France or abroad, or from public or private research centers.
L'archive ouverte pluridisciplinaire $\mathbf{H A L}$, est destinée au dépôt et à la diffusion de documents scientifiques de niveau recherche, publiés ou non, émanant des établissements d'enseignement et de recherche français ou étrangers, des laboratoires publics ou privés. 


\section{Author's Accepted Manuscript}

Fluorophosphate glasses containing manganese

T. Djouama, A. Boutarfaia, M. Poulain

PII: $\quad$ S0022-3697(08)00352-1

DOI: $\quad$ doi:10.1016/j.jpcs.2008.07.004

Reference: $\quad$ PCS 5655

To appear in: Journal of Physics and Chemistry of Solids

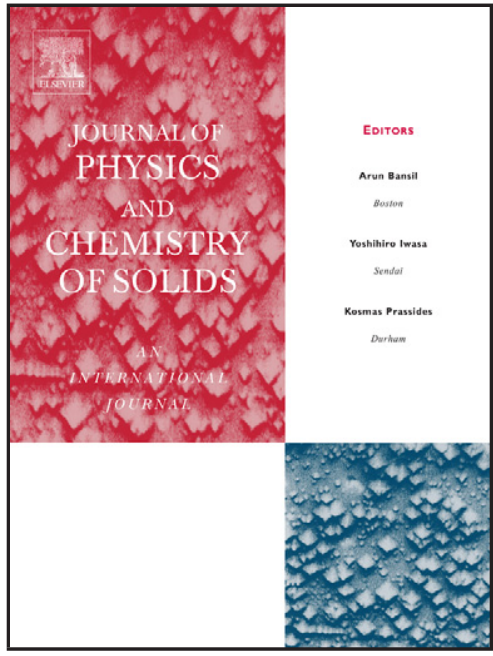

www.elsevier.com/locate/jpcs

Received date: $\quad 12$ July 2007

Revised date: $\quad 22$ May 2008

Accepted date: $\quad 3$ July 2008

Cite this article as: T. Djouama, A. Boutarfaia and M. Poulain, Fluorophosphate glasses containing manganese, Journal of Physics and Chemistry of Solids (2008), doi:10.1016/j.jpcs.2008.07.004

This is a PDF file of an unedited manuscript that has been accepted for publication. As a service to our customers we are providing this early version of the manuscript. The manuscript will undergo copyediting, typesetting, and review of the resulting galley proof before it is published in its final citable form. Please note that during the production process errors may be discovered which could affect the content, and all legal disclaimers that apply to the journal pertain. 


\title{
Fluorophosphate Glasses containing Manganese
}

\author{
T. Djouama ${ }^{1,2}$, A. Boutarfaia and M.Poulain ${ }^{1}$ \\ 1 Sciences Chimiques, Bat 10B, Campus Universitaire Beaulieu, F-35042 Rennes \\ ${ }^{2}$ Laboratoire chimie Appliquée, Université M. Khider, BP 145, RP 07000 Biskra, Algérie.
}

\begin{abstract}
New fluorophosphate glasses based on $\mathrm{MnF}_{2}, \mathrm{NaPO}_{3}$ and $M \mathrm{~F}_{\mathrm{n}}\left(M=\mathrm{Zn}^{2+}, \mathrm{Sr}^{2+}, \mathrm{Mg}^{2+}\right.$, $\mathrm{Ba}^{2+}, \mathrm{Li}^{+}, \mathrm{Na}^{+}$and $\mathrm{K}^{+}$) have been synthesised and characterized. Large vitreous areas were observed. Samples of $4 \mathrm{~mm}$ in thickness have been obtained. These glasses are easy to prepare and stable in ambient air. Depending on the composition and the nature of the $M$ cation, glass transition temperature, $\mathrm{Tg}$, lies between 230 and $314^{\circ} \mathrm{C}$, crystallisation temperature, $\mathrm{Tx}$ is between 320 and $475^{\circ} \mathrm{C}$. These glasses are pink coloured, and infrared transmission extends up to $4.5 \mu \mathrm{m}$ with extrinsic $\mathrm{OH}^{-}$absorption band at $3200 \mathrm{~cm}^{-1}$ and other bands around 2200 and $1600 \mathrm{~cm}^{-1}$ that relate to $\mathrm{PO}_{4}$ tetrahedron vibration. Other physical properties including density, microhardness, Young modulus, thermal expansion and refractive index were investigated and correlated to composition.
\end{abstract}

Key words: fluorophosphate glasses, thermal properties, optical properties, IR transmission, physical properties.

\section{Introduction}

Numerous fluorophosphate glasses have been studied for their potential applications [1-5]. Most of them are based on alkali, earth alkali or trivalent polyphosphates with the general formula $\mathrm{M}\left(\mathrm{PO}_{3}\right)_{\mathrm{n}}$, with $\mathrm{n}=1,2$ or 3 . Among other features, they may have a good transmission in the UV spectrum [4] and host rare earth cations, leading to active optical devices.

This study focuses on fluorophosphate glasses containing manganese difluoride $\mathrm{MnF}_{2}$, both for fundamental studies and for special optical uses, taking advantage of fluorescence and magnetic properties of divalent manganese.

The starting point of our work is the glass formation in binary fluoride systems that combine $\mathrm{MnF}_{2}$ with other fluorides [6]. While such glasses have been characterized, their stability against devitrification is limited as they require fast cooling rates, which does not allow thick samples to be obtained. The incorporation of sodium polyphosphate $\left(\mathrm{Na}\left(\mathrm{PO}_{3}\right)\right)_{\mathrm{n}}$ 
appears as a simple way to increase glass stability, as this has already been reported in the $\mathrm{Na}\left(\mathrm{PO}_{3}\right)-\mathrm{BaF}_{2}-\mathrm{MnF}_{2}$ ternary system [7]. This additive keeps a low temperature of melting, which limits fluorine losses that occur with the formation of gaseous $\mathrm{POF}_{3}$. While pure $\mathrm{Na}\left(\mathrm{PO}_{3}\right)$ glass is somewhat sensitive to water, the incorporation of insoluble fluoride increases chemical durability, especially in wet atmosphere: sample surface remains clear even at high relative humidity.

The systematic investigation of the glass forming ranges in the ternary systems $\mathrm{MnF}_{2}$ $\mathrm{NaPO}_{3}-M \mathrm{~F}_{\mathrm{n}}\left(M=\mathrm{Zn}^{2+}, \mathrm{Sr}^{2+}, \mathrm{Mg}^{2+}, \mathrm{Ba}^{2+}, \mathrm{Li}^{+}, \mathrm{Na}^{+}\right.$and $\left.\mathrm{K}^{+}\right)$has been carried out. The evolution of the physical properties versus chemical composition has also been implemented.

\section{Experimental}

\section{Starting Materials}

Fluorides $\mathrm{ZnF}_{2}, \mathrm{SrF}_{2}, \mathrm{MgF}_{2}, \mathrm{BaF}_{2}, \mathrm{NaF}, \mathrm{LiF}$ and $\mathrm{KF}$ are commercial products from ALDRICH and WWR, with a $99.9 \%$ purity. Ammonium hydrogenofluoride $\mathrm{NH}_{4} \mathrm{~F}$.HF is from Riedel de Haen and from WWR (Prolabo).

Manganese difluoride has been synthesized in the laboratory, using $\mathrm{MnO}$ and $\mathrm{NH}_{4} \mathrm{~F}$. $\mathrm{HF}$ as a fluorinating reagent in a platinum crucible, and controlled by X-Ray diffraction.

\section{Glass synthesis}

Glasses are prepared at room atmosphere using the ammonium bifluoride processing [8]. The calculated amount of the starting materials is introduced in a long platinum crucible with an excess of $\mathrm{NH}_{4} \mathrm{~F}, \mathrm{HF}$. This reagent acts as a fluorinating reagent to convert oxides in fluorides and also to protect the melt from atmospheric hydrolysis. After melting is complete, a clear liquid is obtained. Then this liquid is briefly heated at higher temperature for the fining step and cooled into the crucible to a temperature low enough to have larger viscosity without visible crystallization. Finally it is cast onto a brass mould and squeezed by another metallic plate. The resulting sample corresponds to a "quenched glass"; its thickness lies between 0.4 and $1 \mathrm{~mm}$, and effective cooling rate may reach $1000 \mathrm{~K} . \mathrm{s}^{-1}$. Thicker samples are obtained when melt is cast between two brass walls that are heated at temperature close to Tg. A final annealing stage is carried out for 6 hours at temperature : $\mathrm{T}_{\mathrm{a}}=(\mathrm{Tg}-10)^{\circ} \mathrm{C}$, to remove residual thermal stresses prior to polishing.

\section{Characterizations}

Characteristic temperatures ( $\mathrm{Tg}$ for glass transition, Tx for onset of crystallization and $\mathrm{Tp}$ for maximum of crystallization peak) were determined by differential scanning calorimeter (DSC) using a SEIKO DSC/220 set-up. The estimated error on the temperature is $2 \mathrm{~K}$ for glass transition and onset of crystallization which are obtained from tangents intersection and $1 \mathrm{~K}$ for the position of the crystallization peak. Samples, 10 to $20 \mathrm{mg}$ in weight, were set in aluminum pans under $\mathrm{N}_{2}$ atmosphere at $10 \mathrm{~K} / \mathrm{min}$ heating rate.

Thermal expansion is measured using a TMA 2840 (TA Instruments) set-up, at $2 \mathrm{~K} / \mathrm{min}$ heating rate, between $50{ }^{\circ} \mathrm{C}$ and $200{ }^{\circ} \mathrm{C}$. Estimated experimental error is $\Delta \alpha= \pm 2 \times 10^{-7} \mathrm{~K}^{-1}$. The densities were determined by gas pycnometry using He (Micromeritics Accupyc), with a precision of about $10^{-4}$. Microhardness (Vickers) is measured using a Matsuzawa MXT set-up with $50 \mathrm{~g}$ applied load for 10 seconds. A mean value is obtained after averaging several 
measurements. Young $(\boldsymbol{E})$, Shear $(\boldsymbol{G})$ modulus, and Poisson ratio (v) of samples are obtained from ultrasonic measurements using the ultrasonic pulse-echo method.

Infrared transmission spectra were recorded with a BOMEM Michelson Spectrophotometer in the $5000-2000 \mathrm{~cm}^{-1}$ range. Glass samples were either plates, 1 to $3 \mathrm{~mm}$ in thickness, or powdered glass in KBr pellets. UV transmission between 300 and $500 \mathrm{~nm}$ was studied using a Varian spectrophotometer Cary 5. In both cases, data were given directly in transmittance and/or absorbance. Refractive index in the visible spectrum, $\mathrm{n}_{\mathrm{D}}(\lambda=0.5893$ $\mu \mathrm{m})$, was measured using an Abbe refractometer.

The chemical composition of glasses has been checked by element analysis using energy dispersion spectrometry EDS (Oxford Link ISIS) set-up incorporated into the ISM 6400 Jeol scanning electron microscope.

\section{Results}

\subsection{Glass formation in the $\mathrm{MnF}_{2}-\mathrm{NaPO}_{3}-M \mathrm{~F}_{\mathrm{n}}$ ternary systems.}

- Vitreous areas

Glass forming ranges have been investigated in ternary systems $\mathrm{MnF}_{2}-\mathrm{NaPO}_{3}-M \mathrm{~F}_{\mathrm{n}}(M=$ $\mathrm{Zn}, \mathrm{Sr}, \mathrm{Mg}$ and $\mathrm{Ba}$; $\mathrm{Li}, \mathrm{Na}$ and $\mathrm{K}$ ). Experimental results are gathered in Fig. 1a-g. Glass formation limits depend on cooling rate. Larger cooling rates are required when devitrification rate increases, that is for less stable glasses. Note that $\mathrm{NaPO}_{3}$ itself may form a glass, and consequently makes the starting point for all vitreous areas.

Manganese-containing glasses are pink and become darker at higher Mn content. Samples are stable at room atmosphere, except for a few compositions with high $\mathrm{NaPO}_{3}$ concentration and $\mathrm{MnF}_{2}$ content lower than $5 \%$.

\section{- Glass compositions}

The chemical composition of the samples is defined by the relative amount of the starting materials. Taking into account the processing temperature, cations ( $\mathrm{Na}, \mathrm{Mn}, \mathrm{Zn}, \mathrm{K}$, $\mathrm{Sr}, \mathrm{Ba}$ ) will not enter the gaseous phase. However there may be exchanges with atmosphere based on oxidation, hydrolysis and volatilization, especially $\mathrm{HF}$ and $\mathrm{POF}_{3}$ molecules may form. Analyses have been carried out on some samples to compare nominal and real compositions. As reported in table 1 for a typical sample, the discrepancy between expected and observed values is limited. Complementary analyses emphasize that phosphorus and fluorine losses are not significant.

\subsection{Thermal Properties}

\subsubsection{Glasses in the $\mathrm{MnF}_{2}-\mathrm{NaPO}_{3}-\mathrm{ZnF}_{2}$ system}

Glass stability versus devitrification may be estimated from the characteristic temperatures measured by DSC. While this assessment is not always accurate, it is widely acknowledged that the Tx-Tg difference between the temperature of glass transition and the onset of crystallization is strongly correlated to crystallization tendency [9]. Systematic measurements have been implemented on glasses from the $\mathrm{MnF}_{2}-\mathrm{NaPO}_{3}-\mathrm{ZnF}_{2}$ system. Typical DSC curves appear in figures 2. The evolution of glass transition temperature $\mathrm{Tg}$ and thermal stability 
range Tx-Tg vs composition is exemplified in figure 3 for two sets of glasses containing 10 and $20 \% \mathrm{~mol} \mathrm{ZnF}_{2}$ respectively, in which manganese fluoride replaces sodium metaphosphate $\mathrm{NaPO}_{3}$. The general trend is that $\mathrm{Tg}$ decreases and $\mathrm{Tx}-\mathrm{Tg}$ increases when $\mathrm{NaPO}_{3}$ is incorporated at the expense of $\mathrm{MnF}_{2}$.

\subsubsection{Glasses in the $30 \mathrm{MnF}_{2}-50 \mathrm{NaPO}_{3}-20 \mathrm{MF}_{n}$ system}

A second set of characterizations has been implemented on ternary fluorophosphate glasses with the general formula $30 \mathrm{MnF}_{2}-50 \mathrm{NaPO}_{3}-20 M \mathrm{~F}_{\mathrm{n}}(M=\mathrm{Li}, \mathrm{Na}, \mathrm{K}, \mathrm{Zn}, \mathrm{Sr}, \mathrm{Ba}, \mathrm{Mg}$. $)$. Most of these glasses may be obtained as thick samples. Figure 4 makes the comparison between the characteristic temperatures and the stability range of these glasses. The lowest $\mathrm{Tg}$ are observed for lithium and zinc fluoride, while maximum stability is obtained with lithium, zinc and barium. Considering the earth alkali cations, the $\mathrm{Tg}$ value drops with increasing ionic radius, from $326^{\circ} \mathrm{C}$ for $\mathrm{Mg}$ to $277^{\circ} \mathrm{C}$ for $\mathrm{Sr}$ and $268^{\circ} \mathrm{C}$ for $\mathrm{Ba}$.

\subsubsection{Glasses in the $30 \mathrm{MnF}_{2^{-}} \times \mathrm{NaPO}_{3^{-}}$y $\mathrm{MF}(\mathrm{M}=$ alkali metal $)$ systems}

Another set of thermal measurements has been implemented to find the optimum alkali concentration to be incorporated in the $\mathrm{MnF}_{2}-\mathrm{NaPO}_{3}$ binary system. While glass forming range is drawn in Fig. 1e-g, samples have been selected with the composition $30 \mathrm{MnF}_{2}-(70-$ $\mathrm{x}) \mathrm{NaPO}_{3}-\mathrm{x} M \mathrm{~F},(\mathrm{x}=10,20,30)$. As shown in figure 5, glass transition temperature and stability factor decrease with rising $M \mathrm{~F}$ content, suggesting that optimum $M \mathrm{~F}$ concentration is close to $10 \%$.

According to the confusion principle, glasses more stable against devitrification should be obtained by the addition of two alkali fluorides instead of one. A series of glass samples has been prepared to investigate this possibility according to the composition rule $30 \mathrm{MnF}_{2}-40$ $\mathrm{NaPO}_{3}-(30-\mathrm{x}) \mathrm{LiF}-\mathrm{xKF}$. Corresponding thermal data that appear in table 2 confirm that these quaternary glasses are more stable than the basic ternary glass.

Note that $\mathrm{Tg}$ increases as $\mathrm{K}$ substitutes $\mathrm{Li}$ and most stable glasses (i.e. larger thermal stability range) correspond to 10 to $15 \% \mathrm{KF}$ content.

\subsection{Other physical properties}

\subsubsection{Density}

- $\quad \mathrm{MnF}_{2}-\mathrm{NaPO}_{3}-\mathrm{ZnF}_{2}$ glass

Two sets of samples have been prepared according to the general formula: $\mathrm{xMnF}_{2}-(80-\mathrm{x})$ $\mathrm{NaPO}_{3}-20 \mathrm{ZnF}_{2}$ and $\mathrm{xMnF}_{2}-(90-\mathrm{x}) \mathrm{NaPO}_{3}-10 \mathrm{ZnF}_{2}$. From figure 6, it appears that density increases as $\mathrm{MnF}_{2}$ substitutes $\mathrm{NaPO}_{3}$, and this evolution is roughly linear, density ranging from 2.80 and $3.36 \mathrm{~g} / \mathrm{cm}^{3}$.

- $\mathrm{MnF}_{2}-\mathrm{NaPO}_{3}-\mathrm{MF}(\mathrm{M}=\mathrm{Li}, \mathrm{K})$ glass

Alkali-containing glasses have been investigated. Incorporation of heavier alkali cations into $\mathrm{MnF}_{2}-\mathrm{NaPO}_{3}-M F$ system leads to decreasing density. Experimental values are reported in table 2 for the $30 \mathrm{MnF}_{2}-40 \mathrm{NaPO}_{3}-(30-\mathrm{x}) \mathrm{LiF}-\mathrm{xKF}$ glasses.

\subsubsection{Thermal expansion}


As reported in table 3, the coefficient of thermal expansion (CTE) of glasses in the $\mathrm{MnF}_{2}$ $\mathrm{NaPO}_{3}-\mathrm{ZnF}_{2}$ system is close to $188 \times 10^{-7} \mathrm{~K}^{-1}$ and variations resulting from composition changes are very small: neither the $\mathrm{NaPO}_{3} / \mathrm{MnF}_{2}$ nor the $\mathrm{ZnF} \mathrm{F}_{2} / \mathrm{MnF}_{2}$ substitutions influence significantly the CTE. But we can say that it increases slightly with the size of the third cation $(\mathrm{Zn}, \mathrm{Sr}, \mathrm{Ba}, \mathrm{K})$. The largest value is observed with the glass containing $\mathrm{BaF}_{2}$. These CTE values are fairly high and compare to those of fluorozirconate glasses.

\subsubsection{Mechanical properties}

The microhardness "Hv" evolution versus $\mathrm{MnF}_{2}$ content is shown in figure 7 for a set of samples with the formula: $\mathrm{xMnF}_{2}-(80-\mathrm{x}) \mathrm{NaPO}_{3}-20 \mathrm{ZnF}_{2}$. There is a linear correlation between microhardness and $\mathrm{MnF}_{2}$ concentration. These values are smaller than those observed for standard fluoride glasses [10].

For the alkali-containing glasses, microhardness increases with the ionic radius of the alkali cation. Indeed, in the glass $30 \mathrm{MnF}_{2}-40 \mathrm{NaPO}_{3}-30 \mathrm{MF}$, the $\mathrm{Hv}$ value grows from 179 to 208 $\mathrm{kg} / \mathrm{mm}^{2}$ when potassium replaces lithium.

Sound velocity has been measured in a series of samples with variable manganese content. Young modulus and Poisson ratios are deduced from these measurements. Results are reported in table 4 and show that these moduli are larger at high $\mathrm{MnF}_{2}$ content. Young modulus ranges between 39 an $60 \mathrm{GPa}$, which is close to the values measured for fluoride glasses [11].

\subsubsection{Chemical durability}

Samples are stable at room atmosphere. However, some compositions may be sensitive to high relative humidity, for example the $80 \mathrm{NaPO}_{3}-20 \mathrm{ZnF}_{2}$ glass and more generally samples with high $\mathrm{NaPO}_{3}$ concentration. The surface corrosion that occurs may be the result of water condensation. A set of qualitative tests has been implemented on various samples, based on immersion in deionised water at $20^{\circ} \mathrm{C}$ for 48 hours. The general trend is that corrosion layer is smaller when manganese fluoride content increases. $\mathrm{NaPO}_{3}, \mathrm{KF}$ and $\mathrm{NaF}$ enhance water attack. For example, using the $30 \mathrm{MnF}_{2}-50 \mathrm{NaPO}_{3}-20 \mathrm{ZnF}_{2}$ composition, the weight loss of a glass sample, $2.6 \mathrm{~g}$ in weight and $7 \mathrm{~cm}^{2}$ in outer surface, is only $1 \mathrm{mg}$.

\subsection{Optical properties}

\subsubsection{Refractive index}

Refractive index has been measured for samples of variable composition in the $\mathrm{MnF}_{2}$ $\mathrm{NaPO}_{3}-\mathrm{ZnF}_{2}$. system. As shown in figure 8a, it increases from 1.50 to 1.52 when $\mathrm{MnF}_{2}$ substitutes $\mathrm{NaPO}_{3}$. By comparison, alkali-containing glasses have a lower refractive index. For example, we measured $\mathrm{n}_{\mathrm{D}}=1.516$ for $30 \mathrm{MnF}_{2}-50 \mathrm{NaPO}_{3}-20 \mathrm{ZnF}_{2}$ glass while it is only 1.480 for the $30 \mathrm{MnF}_{2}-50 \mathrm{NaPO}_{3}-20 \mathrm{KF}$ glass. Higher values are obtained with lithium as this is shown in figure $8 \mathrm{~b}$ for the $30 \mathrm{MnF}_{2}-40 \mathrm{NaPO}_{3}-(30-\mathrm{x}) \mathrm{LiF}-\mathrm{xKF}$ glasses.

\subsubsection{Optical transmission}




\section{a) UV-Visible transmission}

Divalent manganese induces optical absorption in the UV-visible spectrum. This is exemplified by figure 9 that shows the transmission spectra of samples containing an increasing amount of $\mathrm{Mn}^{2+}$. Binary $\mathrm{NaPO}_{3}-\mathrm{ZnF}_{2}$ glass is colourless and the UV cut-off is below $300 \mathrm{~nm}$. The UV absorption edge is shifted towards longer wavelength as $\mathrm{MnF}_{2}$ concentration increases. Curves show one shoulder at $350 \mathrm{~nm}$ and two absorption bands located around 400 and $500 \mathrm{~nm}$ that correspond to transitions of $\mathrm{Mn}^{2+}$ ions in octahedral sites $[12,13]$.

\section{b) Infrared transmission}

- Bulk samples

The transmission spectrum of the $30 \mathrm{MnF}_{2}-50 \mathrm{NaPO}_{3}-20 \mathrm{ZnF}_{2}$ glass has been recorded between 100 and $5000 \mathrm{~cm}^{-1}$ and is reproduced in figure 10. The thinner sample (dashed line) evidences the complex structure of the absorption bands.

The main features that emerge from this figure are:

- The absorption band around $3200 \mathrm{~cm}^{-1}$ that originates from hydroxyl groups.

- An intense band at $2200 \mathrm{~cm}^{-1}$ that defines the transmission limit of the sample.

- Another band around $1600 \mathrm{~cm}^{-1}$.

- Powdered samples

Infrared transmission of powdered samples of the same glass in $\mathrm{KBr}$ pellets is shown in figure 11. The spectrum is limited to $400 \mathrm{~cm}^{-1}$, as $\mathrm{KBr}$ is no more transparent beyond this frequency. The comparison with bulk glass shows that the absorption observed between 1500 and $2500 \mathrm{~cm}^{-1}$ corresponds to the first overtones of the fundamental absorption bands of the $\mathrm{PO}_{4}$ tetrahedra $[14,15]$.

\section{Discussion}

As one could expect, sodium polyphosphate makes an efficient stabilizer of the fluoride glasses based on $\mathrm{MnF}_{2}$. Thick samples can be obtained, which facilitates mechanical and optical measurements.

The evolution of the physical properties versus composition logically relates to the intrinsic features of the chemical elements and also to glass structure. Main elements may be summarized as follows:

1) Phosphorus forms tetrahedra $\mathrm{PX}_{4}$ in which $\mathrm{X}=\mathrm{O}$ or $\mathrm{F}$, predominantly $\mathrm{O}$.

2) Manganese and zinc form $\mathrm{MnX}_{6}$ octahedra $\left(\mathrm{M}=\mathrm{O}\right.$ or $\mathrm{F}$ ) and $\mathrm{ZnF}_{6}$ octahedra respectively [16].

3) Sodium is considered as a network modifier, and its coordination number is large in the solid state: from 6 in $\mathrm{NaF}$ to 12 in $\mathrm{NaWO}_{3}$ [17].

4) Bond strength of $\mathrm{P}-\mathrm{O}(110 \mathrm{kcal} / \mathrm{mol})$ bond is larger than that of $\mathrm{Mn}-\mathrm{O}, \mathrm{Zn}-\mathrm{O}$ and $\mathrm{Na}-\mathrm{O}$ bonds [18].

5) Ionic radii [19] of $\mathrm{Mn}^{2+}$ and $\mathrm{Zn}^{2+}$ are close: 83 and $72 \mathrm{pm}$ respectively.

6) The structure of the polyphosphate glasses is reported to consist of long $\left(\mathrm{PO}_{3}\right)_{\mathrm{n}}$ chains in which tetrahedra - labelled $\mathrm{Q}^{2}$ in NMR studies - have 2 bridging and 2 non bridging oxygens. These chains bring negative charges that are balanced by the positive anionic charges (e.g. $\left.\mathrm{Na}^{+}\right)$. Due to the low connectivity of the vitreous network, Tg is usually low: $260{ }^{\circ} \mathrm{C}$ in vitreous $\mathrm{NaPO}_{3}[20]$. 
7) Vibrational spectroscopy, especially infrared transmission, has been used to provide structural information about fluorophosphate glasses. Studies confirm that fluorides lead to the depolymerization of the polyphosphate chains [21-24]. Fluorides are known to lower network connectivity by creating terminal P-F bonds that take place of P-O-P bridges.

8) In manganese fluoride glasses, the vitreous network is made from $\mathrm{MnF}_{6}$ octahedra sharing corners [16]. The connectivity is large to account for the chemical formula: in crystalline $\mathrm{MnF}_{2}$, each corner is shared by 3 octahedra, while all fluorine anions are bridging for a $\mathrm{MnF}_{3}$ network. Non bridging fluorines appear when the network formula is $\mathrm{MnF}_{3+\mathrm{x}}$. This large connectivity accounts for the high $\mathrm{Tg}$ of these glasses, for example $377{ }^{\circ} \mathrm{C}$ for the $70 \mathrm{MnF}_{2}-30 \mathrm{BaF}_{2}$ binary glass [6].

The evolution of the glass transition temperature versus composition is consistent with these statements. Its value depends on the factors that rule the sensitivity of the structure to thermal motion, namely bond strength and network connectivity. The structure of these glasses may be described as a hybrid network constructed from the association of $\mathrm{PX}_{4}$ tetrahedra and $\mathrm{MnF}_{6}$ octahedra. In these materials, glass transition temperature is close to $250{ }^{\circ} \mathrm{C}$. In a general way it decreases as $\mathrm{NaPO}_{3}$ concentration increases (figure 3). Note that $\mathrm{Tg}$ of the $80 \mathrm{NaPO}_{3}-20 \mathrm{ZnF} 2$ glass is lower than that of pure $\mathrm{NaPO}_{3}$. The Tg decrease exemplifies the depolymerisation of the $\mathrm{PO}_{3}$ chain by fluorine that creates non bridging anions through the formation of $\mathrm{PO}_{3} \mathrm{~F}$ tetrahedra. As $\mathrm{MnF}_{2}$ content increases, the concentration of modifying cations $\left(\mathrm{Na}^{+}\right)$decreases and connectivity increases, which logically results in higher $\mathrm{Tg}$. When $\mathrm{MnF}_{2}$ substitutes $\mathrm{NaPO}_{3}$, the evolution of Tg is nearly linear versus $\mathrm{MnF}_{2}$ content up to $30 \mathrm{~mol} \%$ (fig. $3 \mathrm{~b}$ ). Beyond this value Tg increases faster, which suggests that there is a structural change beyond this limit. This could correspond to the formation of $\operatorname{Mn}(\mathrm{O}, \mathrm{F})_{6}$ octahedra including the non bridging oxygen of the $\mathrm{PO}_{4}$ tetrahedra. Anyway it also indicates the transition from a chain structure to a tridimensional network. Note also that, for the same nominal composition, glass transition temperature is higher with large and heavy alkali cations (figure 4) and Tg increases as KF substitutes LiF (table 2). The similar trend has been observed in various halide systems [25-27].

While introduction of $\mathrm{NaPO}_{3}$ clearly improves resistance to devitrification, the stability of the glass versus devitrification is not unambiguously correlated to composition. It rather increases as the number of component increases, in agreement with the confusion principle. This may explain why thermal stability range is smaller with $\mathrm{NaF}$ than with $\mathrm{LiF}$ and $\mathrm{KF}$ (figure 5): sodium from $\mathrm{NaPO}_{3}$ enters glass composition and $\mathrm{NaF}$ incorporation does not increase the number of different cations.

The $\mathrm{MnF}_{2} / \mathrm{NaPO}_{3}$ substitution increases microhardness and Young modulus. One may assume that the decrease in the concentration in monovalent cation $\left(\mathrm{Na}^{+}\right)$and linear chain $\left(\mathrm{PO}_{3}\right)^{-}$results in larger lattice energy. The larger network connectivity reported above has the same influence.

Density increases as $\mathrm{MnF}_{2}$ replaces $\mathrm{NaPO}_{3}$, which is partly explained by the smaller atomic weight and the larger size of $\mathrm{Na}$ by comparison to $\mathrm{Mn}$. In the same way, density increases when zinc content rises from 10 to $20 \mathrm{~mol} \%$ at the expense of $\mathrm{NaPO}_{3}$ (figure 6). This evolution is consistent with the density values of the crystalline materials: 2.6 for $\mathrm{NaPO}_{3}, 3.9$ for $\mathrm{MnF}_{2}$ and 4.9 for $\mathrm{ZnF}_{2}$ [28]. The $\mathrm{K} / \mathrm{Li}$ substitution also leads to smaller density (table 2). Although the alkali atomic mass of potassium is larger, the size effect is predominant and decreases molar volume. 
Optical transmission is restricted to the visible spectrum because the electronic transitions of $\mathrm{Mn}^{2+}$ cations in octahedral ligand field lead to strong UV absorption [12,13]. It is limited to 4.5 micrometers in the mid-infrared by the first overtone of the P-O vibrations, as this has been shown in fluoride glasses doped with phosphates [14,15,29].

Thus, these glasses may be used as filters. They contain large amounts of divalent manganese, and further studies could focus on possible magneto-optic or photo-induced phenomena in addition to the more classical fluorescence.

\section{Conclusion}

Bulk glasses rich in manganese $\left(>30 \mathrm{~mol} \% \mathrm{MnF}_{2}\right.$ ) have been obtained in the $\mathrm{MnF}_{2}$ $\mathrm{NaPO}_{3}-M \mathrm{~F}_{\mathrm{n}}$ systems, with $M=\mathrm{Ba}, \mathrm{Sr}, \mathrm{Zn}, \mathrm{Li}, \mathrm{Na}, \mathrm{K}$. Glass transition temperature is close to $250{ }^{\circ} \mathrm{C}$ and depends on composition. Main physical properties, including density, refractive index $\mathrm{n}_{\mathrm{D}}$, microhardness, and thermal expansion, have been measured. The incorporation of manganese fluoride at the expense of $\mathrm{NaPO}_{3}$ leads to the increase of $\mathrm{Tg}, \mathrm{n}_{\mathrm{D}}, \mathrm{E}$ (Young modulus) and microhardness, while chemical durability is enhanced. Optical transmission is limited in the UV spectrum by electronic transitions of $\mathrm{Mn}^{2+}$ ions in octahedral environment and in the IR spectrum by the P-O vibrations.

\section{References}

[1] W. Jahn, Glatech. Ber., 34 (1961) 107.

[2] L. Cook, M. Liepmann and A. J. Marker, Mat. Sci. Forum, 19-20 (1987) 305.

[3] J. Jiang, G. Zhang and M. J. Poulain, J. Non-Cryst. Solids, 213-214 (1997) 11.

[4] L. Cook, K. H. Mader, J. Amer. Ceram. Soc., 65 (1982) 597.

[5] J. Leissner, K. Sebastian, H. Roggendorf and H. Schmidt, Mat. Sci. Forum, 67-68, (1991) 137.

[6] T. Djouama, A. Boutarfaia, M. Poulain, J. Optoelectron Adv. M. - Rapid comm. (OAMRC) 1 (2007) 122.

[7] M. Matecki and M. Poulain, J. Non-Cryst. Solids, 56 (1983) 111.

[8] M.Poulain and G. Mazé, Chemtronics, 3 (1988) 77.

[9] A. Dietzel, Glastech Ber., 22 (1968) 41.

[10] W. L. Vaughn and S. H. Risbud, Mat. Sci. Forum 5 (1985) 159.

[11] J. M. Parker and P. W. France in "Fluoride Glass Optical Fibres", P. W. France Ed, Blackie, Glasgow, 1989, pp 53.

[12] L. N. Feuerhelm, S. M. Sibley, and W. A. Sibley, J. Solid State Chem., 54 (1984) 164.

[13] M. A Bunuel, R. Alcala and R. Cases, J. Phys.: Condens. Matter 10, (1998) 9343.

[14] G. Poirier, M. Poulain, Y. Messaddeq, S. J. L Ribeiro, J. Non-Cryst. Solids 351 (2005) 293.

[15] M. Nalin, Y. Messaddeq, S.J.L. Ribeiro, M. Poulain, V. Briois, J. Optoelectron. Adv. M. 3 (2001) 553.

[16] A. Le Bail, C. Jacoboni, C. and R. De Pape, Mat. Sci. Forum , 5-6 (1985) 441. 
[17] A.F. Wells, Structural Inorganic Chemistry, Clarendon Press, Oxford, 1975

[18] K. H. Sun, J. Am. Ceram. Soc, 30 (1947) 277

[19] R.D. Shannon, Acta Crystallogr. A, 32 (1976) 751

[20] R.K. Brow and Z. A. Osbone, R. J. Kirkpatrick, J.Mater. Res., 7, (1992) 1892

[21] G. Fuxi and C. Hai Yan, Mat. Sci. Forum 1985, 5-6 (1985) 495

[22] B. Karmakar, P. Kundu, and R. N. Dwivedi, J. Am. Ceram. Soc., 83 (2000) 1305

[23] J. J. Videau, J. Portier and C. Fouassier, Mat. Res. Bull., 14 (1979) 177

[24] F. Gan, Y. Jiang \& F. Jiang, J. Non-Cryst. Solids., 52 (1982) 263.

[25] C. A. Angell and D. C. Ziegler, Mat. Res. Bull, 16 (1981) 279

[26] A. Elyamani, M. Poulain, S. J. Saggese and G. H. Siegel, J. Non-Cryst. Solids, 119 (1990) 187

[27] M. Matecki, M.A. Poulain and M. J. Poulain, Mat. Sci. Forum 19-20 (1987) 47

[28] Handbook of Chemistry and Physics, $58^{\text {th }}$ Ed., CRC Press, Boca Raton, 1978

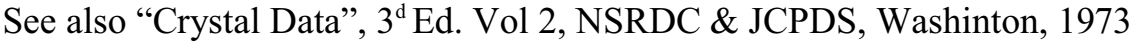

[29] M. Poulain and M. Saad, J Ligtwave Techn., 2 (1984) 599 


\section{Tables}

Table 1

Comparison between nominal and analysed cationic and anionic compositions for a ternary glass.

\begin{tabular}{c|ccccccc}
\hline $\begin{array}{c}\text { Composition } \\
(\% \mathrm{~mol})\end{array}$ & $\begin{array}{c}\boldsymbol{M n} \\
(\% \mathrm{cat})\end{array}$ & $\begin{array}{c}\boldsymbol{Z n} \\
(\% \mathrm{cat})\end{array}$ & $\begin{array}{c}\boldsymbol{N a} \\
(\% \mathrm{cat})\end{array}$ & $\begin{array}{c}\boldsymbol{P} \\
(\% \mathrm{cat})\end{array}$ & $\begin{array}{c}\boldsymbol{O} \\
(\% \mathrm{an})\end{array}$ & $\begin{array}{c}\boldsymbol{F} \\
(\% \mathrm{on})\end{array}$ & \\
\hline $\mathrm{MnF}_{2}-\mathrm{NaPO}_{3}-\mathrm{ZnF}_{2}$ & 28.6 & 14.3 & 28.6 & 28.6 & 50 & 50 & Nominal \\
$40-40-20$ & 24.3 & 15.4 & 30.3 & 30.0 & 48.3 & 51.7 & Analysed \\
\hline
\end{tabular}

Table 2

Characteristic temperatures and densities of $30 \mathrm{MnF}_{2}-40 \mathrm{NaPO}_{3}-(30-\mathrm{x}) \mathrm{LiF}-\mathrm{x} \mathrm{KF}$ glasses. $\mathrm{Tg}$ for glass transition, $\mathrm{Tx}$ for onset of crystallization, $\mathrm{Tp}$ for exotherm maximum.

\begin{tabular}{lllllll}
\hline Sample & $\begin{array}{l}\boldsymbol{x} \\
(\%)\end{array}$ & $\begin{array}{l}\boldsymbol{T g} \\
\left( \pm 2^{\circ} \mathrm{C}\right)\end{array}$ & $\begin{array}{l}\boldsymbol{T} \boldsymbol{x} \\
\left( \pm 2{ }^{\circ} \mathrm{C}\right)\end{array}$ & $\begin{array}{l}\boldsymbol{T p} \\
\left( \pm 1{ }^{\circ} \mathrm{C}\right)\end{array}$ & $\begin{array}{l}\boldsymbol{T} \boldsymbol{x}-\boldsymbol{T g} \\
\left({ }^{\circ} \mathrm{C}\right)\end{array}$ & $\begin{array}{l}\text { Density } \\
\left(\mathrm{g} / \mathrm{cm}^{3}\right)\end{array}$ \\
\hline MNLK0 & 0 & 200 & 247 & $258 ; 330$ & 47 & 2.958 \\
MNLK5 & 5 & 203 & 276 & $289 ; 331$ & 73 & 2.942 \\
MNLK10 & 10 & 212 & 321 & 328 & 109 & 2.930 \\
MNLK15 & 15 & 211 & 335 & 340 & 124 & 2.919 \\
MNLK 20 & 20 & 214 & 286 & 292 & 72 & 2.912 \\
MNLK 25 & 25 & 213 & 274 & $280 ; 339$ & 61 & 2.905 \\
MNLK 30 & 30 & 233 & 287 & $295 ; 434$ & 53 & 2.894 \\
\hline
\end{tabular}


Table 3

Coefficient of thermal expansion of selected glasses.

\begin{tabular}{|c|c|}
\hline Glass Compositions & $\boldsymbol{\alpha}\left(\mathbf{1 0}^{-7} \boldsymbol{K}^{-1}\right)$ \\
\hline $05 \mathrm{MnF}_{2}-20 \mathrm{ZnF}_{2}-75 \mathrm{NaPO}_{3}$ & 188 \\
$15 \mathrm{MnF}_{2}-20 \mathrm{ZnF}_{2}-65 \mathrm{NaPO}_{3}$ & 189 \\
$25 \mathrm{MnF}_{2}-20 \mathrm{ZnF}_{2}-55 \mathrm{NaPO}_{3}$ & 189 \\
$30 \mathrm{MnF}_{2}-20 \mathrm{ZnF}_{2}-50 \mathrm{NaPO}_{3}$ & 185 \\
$35 \mathrm{MnF}_{2}-20 \mathrm{ZnF}_{2}-45 \mathrm{NaPO}_{3}$ & 188 \\
$40 \mathrm{MnF}_{2}-10 \mathrm{ZnF}_{2}-50 \mathrm{NaPO}_{3}$ & 188 \\
$20 \mathrm{MnF}_{2}-10 \mathrm{ZnF}_{2}-70 \mathrm{NaPO}_{3}$ & 183 \\
$40 \mathrm{MnF}_{2}-20 \mathrm{KF}_{-}-40 \mathrm{NaPO}_{3}$ & 210 \\
$20 \mathrm{MnF}_{2}-10 \mathrm{SrF}_{2}-70 \mathrm{NaPO}_{3}$ & 207 \\
$30 \mathrm{MnF}_{2}-20 \mathrm{BaF}_{2}-50 \mathrm{NaPO}_{3}$ & 226 \\
\hline
\end{tabular}

Table 4

Young $(\boldsymbol{E})$ and shear $(\boldsymbol{G})$ modulus, Poisson ratio $(\boldsymbol{v})$ of fluorophosphate glasses in the $\mathrm{x} \mathrm{MnF}_{2}-(80-\mathrm{x}) \mathrm{NaPO}_{3}-20 \mathrm{ZnF}_{2}$ system. Longitudinal $\boldsymbol{V}_{\boldsymbol{L}}$ and transverse $\boldsymbol{V}_{\boldsymbol{T}}$ velocities are obtained from ultrasonic measurements.

\begin{tabular}{|c|c|c|c|c|c|c|}
\hline $\begin{array}{c}\boldsymbol{M n F}_{\boldsymbol{2}} \\
(\mathrm{mol} \mathrm{\% )}\end{array}$ & $\begin{array}{c}\text { Density } \\
\left(\mathrm{kg} / \mathrm{m}^{3}\right)\end{array}$ & $V_{\boldsymbol{L}}\left(10^{3} \mathrm{~m} / \mathrm{s}\right)$ & $\boldsymbol{V}_{\boldsymbol{T}}\left(10^{3} \mathrm{~m} / \mathrm{s}\right)$ & $\boldsymbol{E}(\mathrm{GPa})$ & $\boldsymbol{G}(\mathrm{GPa})$ & $\boldsymbol{v}$ \\
\hline 0 & 2.783 & 4.32 & 2.34 & 39.3 & 15.2 & 0.290 \\
05 & 2.812 & 4.48 & 2.47 & 43.8 & 17.2 & 0.275 \\
15 & 2.929 & 4.92 & 2.57 & 50.2 & 19.3 & 0.301 \\
20 & 2.999 & 4.59 & 2.60 & 51.6 & 20.2 & 0.276 \\
25 & 3.059 & 4.88 & 2.62 & 53.4 & 21.0 & 0.272 \\
30 & 3.109 & 4.80 & 2.68 & 56.9 & 22.3 & 0.273 \\
35 & 3.205 & 5.10 & 2.63 & 58.4 & 22.2 & 0.317 \\
40 & 3.264 & 4.86 & 2.69 & 60.0 & 23.5 & 0.275 \\
\hline
\end{tabular}




\section{Figures Captions}

Fig. 1. Vitreous areas in ternary systems : $\mathrm{MnF}_{2}-\mathrm{NaPO}_{3}-M \mathrm{~F}_{\mathrm{n}}$ with $M=\mathrm{Zn}$ (a), $\mathrm{Sr}$ (b), $\mathrm{Ba}(\mathrm{c}), \mathrm{Mg}(\mathrm{d}), \mathrm{Na}(\mathrm{e}), \mathrm{Li}(\mathrm{f})$ and $\mathrm{K}(\mathrm{g})$.

Fig. 2. DSC scans of $50 \mathrm{MnF}_{2}-50 \mathrm{NaPO}_{3}(\mathrm{MNZ0})$ and $30 \mathrm{MnF}_{2}-50 \mathrm{NaPO}_{3}-20 \mathrm{ZnF}_{2}(\mathrm{MNZ20})$ glasses. Heating rate: $10 \mathrm{~K} / \mathrm{min}$.

Fig. 3. Evolution of glass transition temperature $\mathrm{Tg}$ and thermal stability range $\mathrm{Tx}-\mathrm{Tg}$ versus $\mathrm{MnF}_{2}$ content: (a) $\mathrm{x} \mathrm{MnF}_{2}-(80-\mathrm{x}) \mathrm{NaPO}_{3}-20 \mathrm{ZnF}_{2}$ and (b) $\mathrm{xnF}_{2}-(90-\mathrm{x}) \mathrm{NaPO}_{3}-$ $10 \mathrm{ZnF}_{2}$.

Fig. 4. Tg and thermal stability range of the $30 \mathrm{MnF}_{2}-50 \mathrm{NaPO}_{3}-20 M \mathrm{~F}_{\mathrm{n}}$ glasses $(M=\mathrm{Li}, \mathrm{K}$, $\mathrm{Mg}, \mathrm{Sr}, \mathrm{Zn}$ and $\mathrm{Ba}$.)

Fig. 5. Glass transition temperature $\mathrm{Tg}$ (a) and thermal stability range $\mathrm{Tx}-\mathrm{Tg}$ (b) versus alkali content in $30 \mathrm{MnF}_{2}-(70-\mathrm{x}) \mathrm{NaPO}_{3}-\mathrm{x} M \mathrm{~F}$ glasses, with $M=\mathrm{Li}, \mathrm{Na}$ and $\mathrm{K}$.

Fig. 6. Evolution of density versus $\mathrm{MnF}_{2}$ content. Glass composition :

(1) $\mathrm{x} \mathrm{MnF}_{2}-(80-\mathrm{x}) \mathrm{NaPO}_{3}-20 \mathrm{ZnF}_{2}$ and (2) $\mathrm{x} \mathrm{MnF}_{2}-(90-\mathrm{x}) \mathrm{NaPO}_{3}-10 \mathrm{ZnF}_{2}$

Fig. 7. Evolution of the Vickers microhardness versus $\mathrm{MnF}_{2}$ concentration in the $\mathrm{xnF}_{2}$ $(80-x) \mathrm{NaPO}_{3}-20 \mathrm{ZnF}_{2}$ system. Line is drawn as a guide to the eye.

Fig. 8. Evolution of refractive index :

(a) vs $\mathrm{MnF}_{2}$ concentration in $\mathrm{x} \mathrm{MnF}_{2}-(80-\mathrm{x}) \mathrm{NaPO}_{3}-20 \mathrm{ZnF}_{2}$ system

(b) $v s \mathrm{KF}$ concentration in $30 \% \mathrm{MnF}_{2}-40 \mathrm{NaPO}_{3}-(30-\mathrm{x}) \mathrm{LiF}-\mathrm{x} \mathrm{KF}$ glasses

Fig. 9. UV-visible absorbance spectra of glasses in the $\mathrm{xMnF}_{2}-50 \mathrm{NaPO}_{3}-(50-\mathrm{x}) \mathrm{ZnF}_{2}$ system. Sample thickness: $2.4 \mathrm{~mm}$.

Fig. 10. IR transmittance spectra of thin $(1 \mathrm{~mm})$ and thick $(\mathrm{e}=2.4 \mathrm{~mm})$ samples of the MNZ20 glass: $30 \mathrm{MnF}_{2}-50 \mathrm{NaPO}_{3}-20 \mathrm{ZnF}_{2}$.

Fig. 11. IR transmittance spectra of $30 \mathrm{MnF}_{2}-50 \mathrm{NaPO}_{3}-20 \mathrm{ZnF}_{2}$ glass

(a) between 400 and $1500 \mathrm{~cm}^{-1}$, (powder dispersed in $\mathrm{KBr}$ )

(b) between 1000 and $4000 \mathrm{~cm}^{-1}$ (1 $\mathrm{mm}$-thick glass plate) 

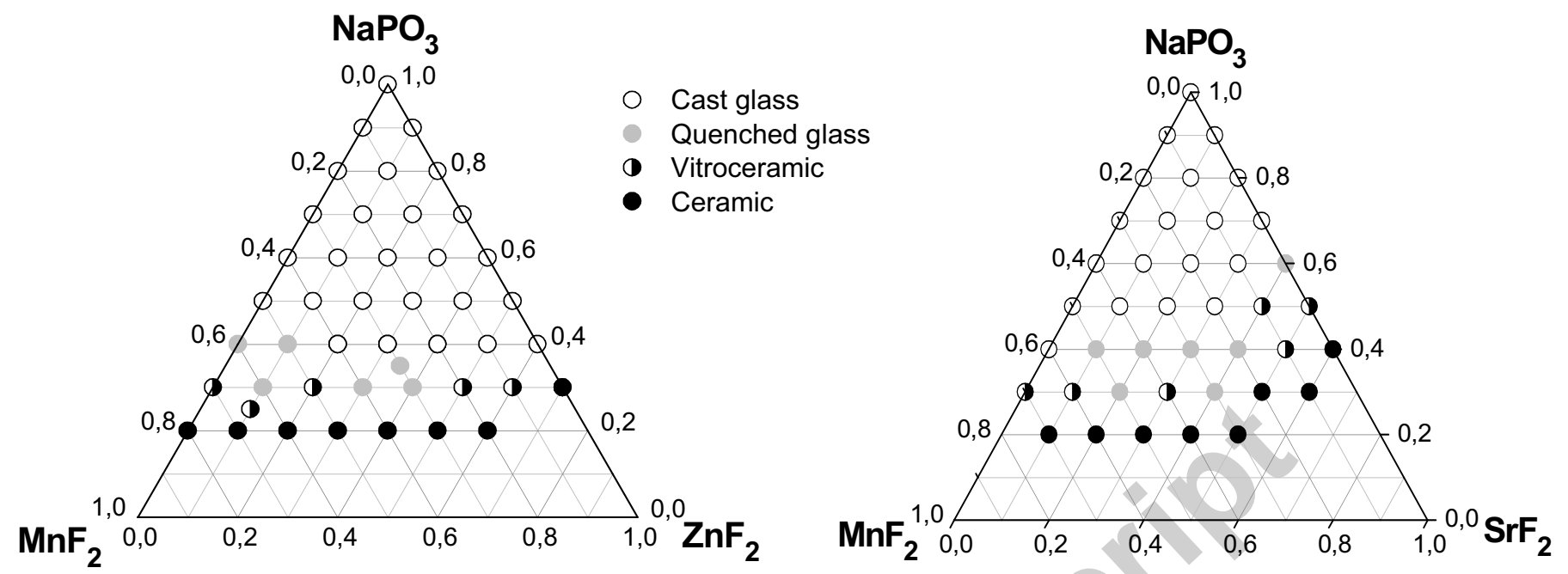

(a)

(b)
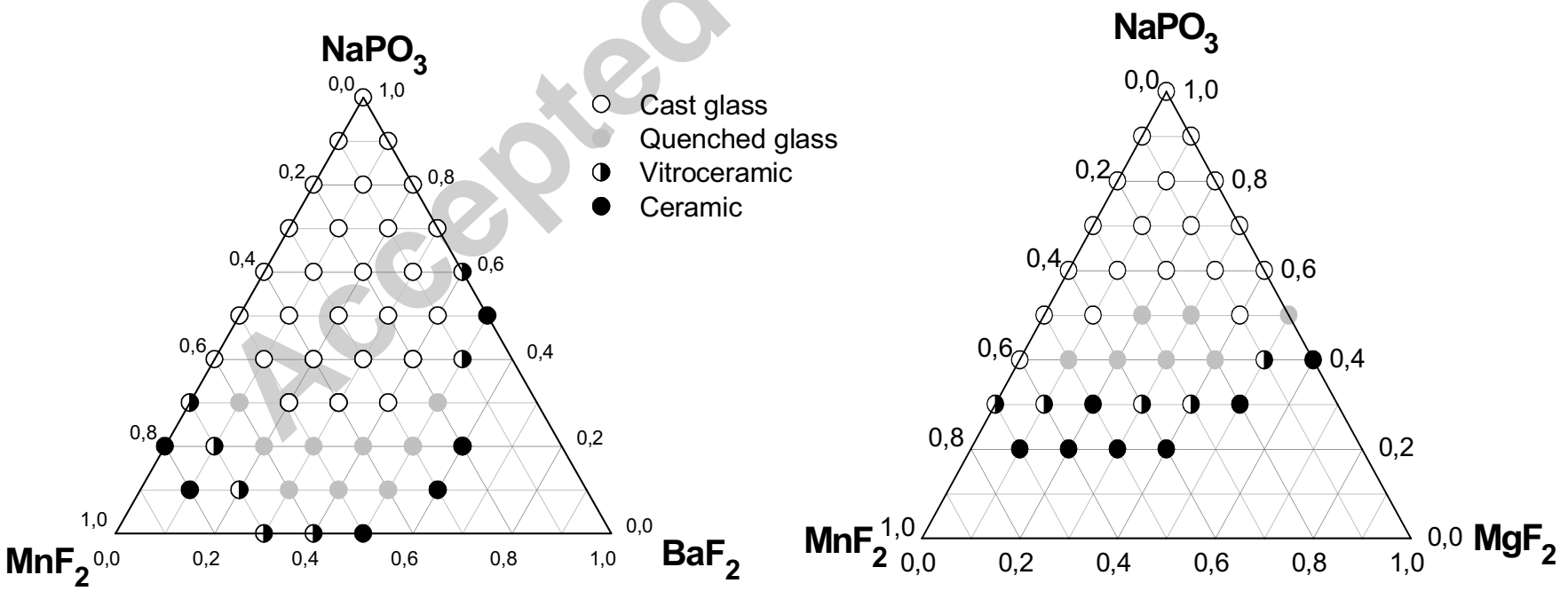

(c)

(d) 


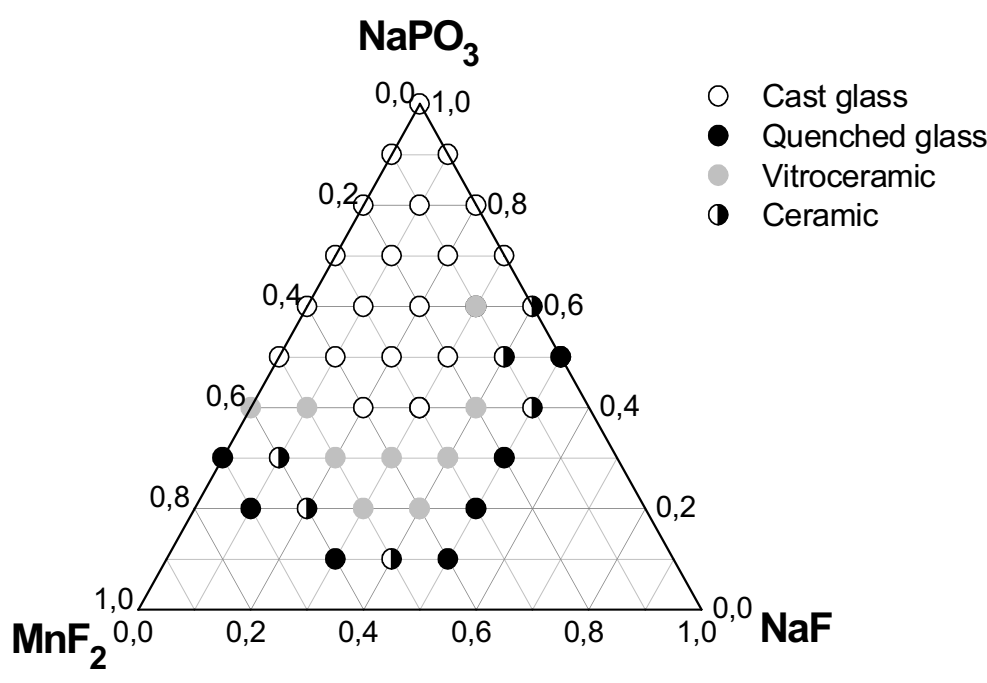

(e)

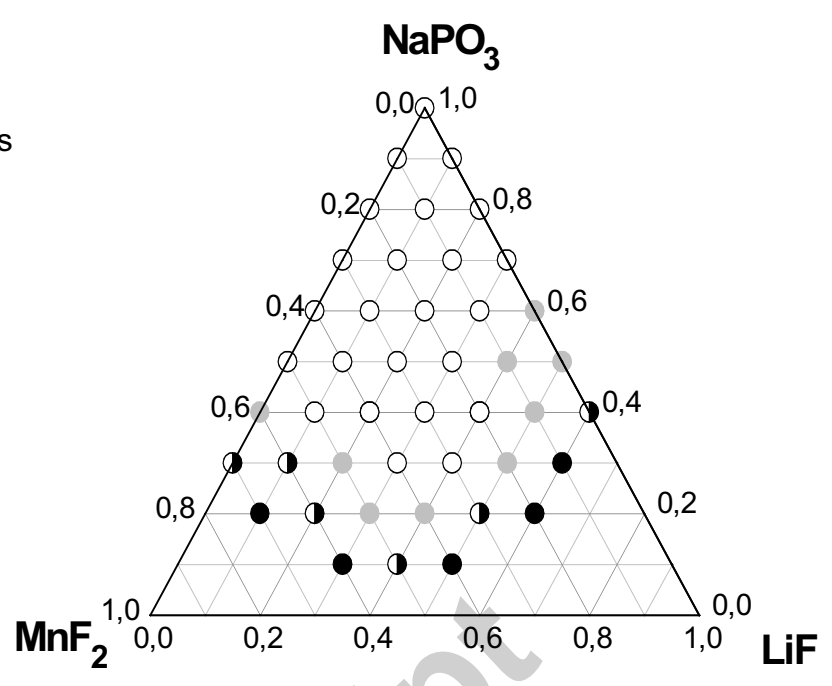

(f)

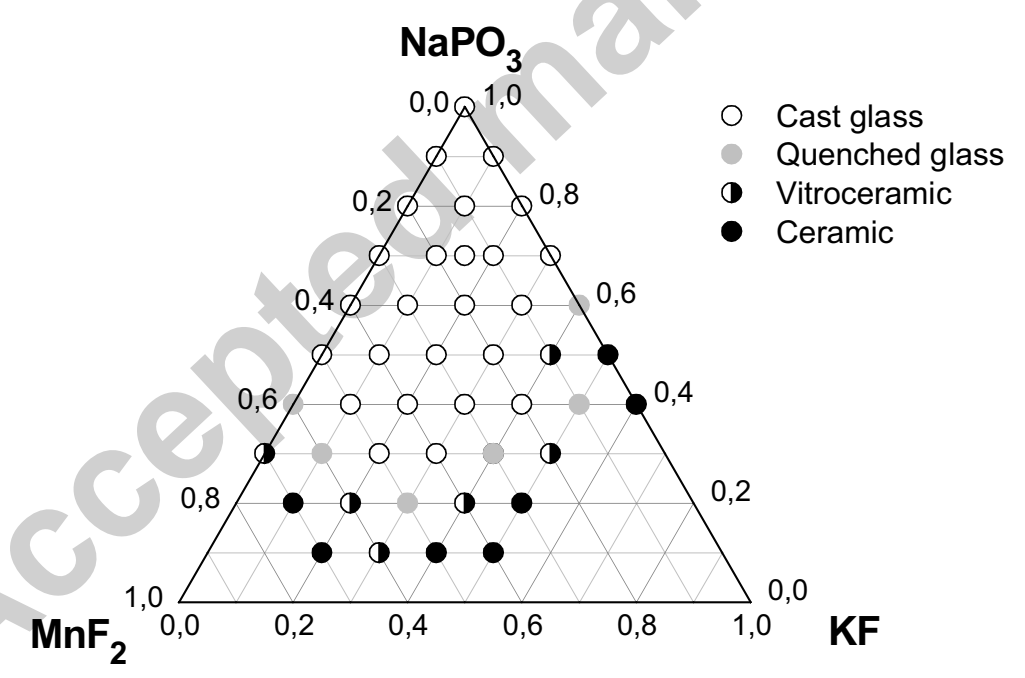

(g)

Fig. 1. Vitreous areas in ternary systems : $\mathrm{MnF}_{2}-\mathrm{NaPO}_{3}-M \mathrm{~F}_{\mathrm{n}}$ with $M=\mathrm{Zn}(\mathbf{a})$; $\mathrm{Sr}(\mathbf{b}) ; \mathrm{Ba}(\mathbf{c}) ; \mathrm{Mg}(\mathbf{d}), \mathrm{Na}(\mathbf{e}) ; \mathrm{Li}(\mathbf{f})$ and $\mathrm{K}(\mathbf{g})$. 


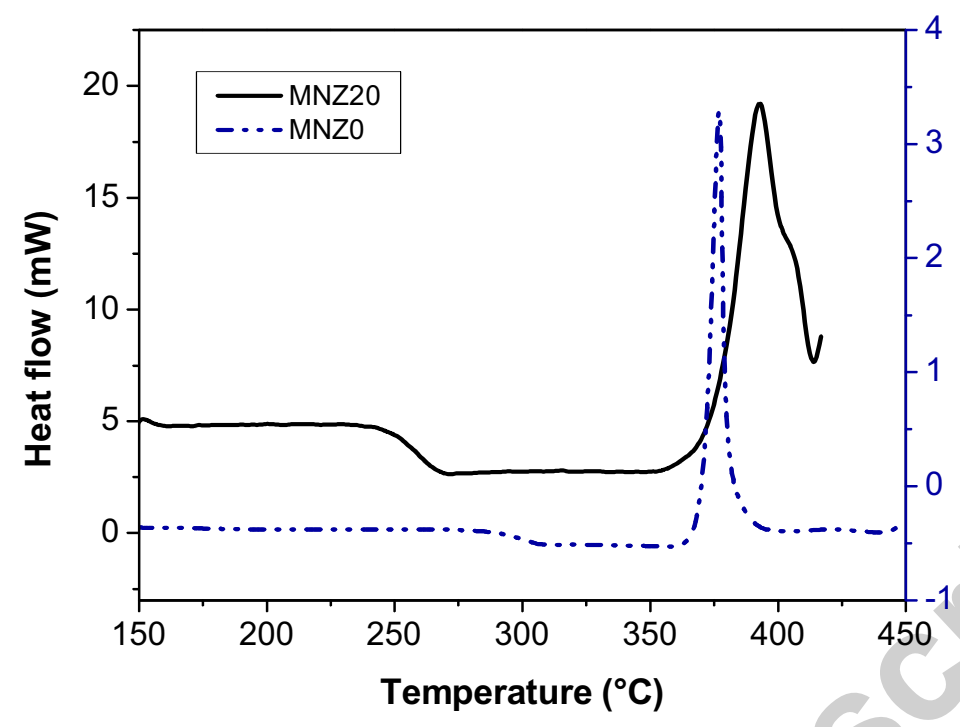

Fig. 2. $\mathrm{DSC}$ scans of $50 \mathrm{MnF}_{2}-50 \mathrm{NaPO}_{3}(\mathrm{MNZ0})$ and $30 \mathrm{MnF}_{2}-50 \mathrm{NaPO}_{3}-20 \mathrm{ZnF}_{2}(\mathrm{MNZ20})$ glasses. Heating rate: $10 \mathrm{~K} / \mathrm{min}$.

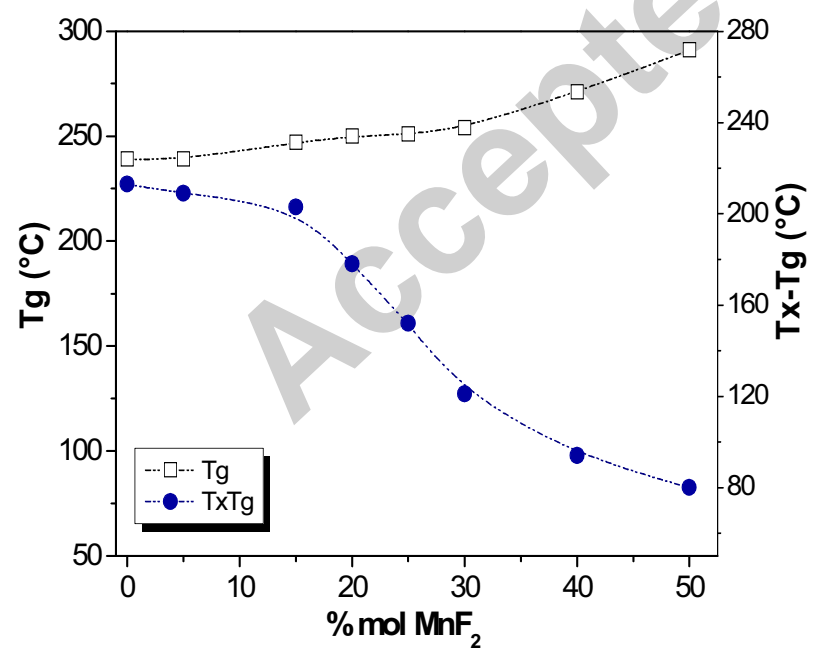

(a)

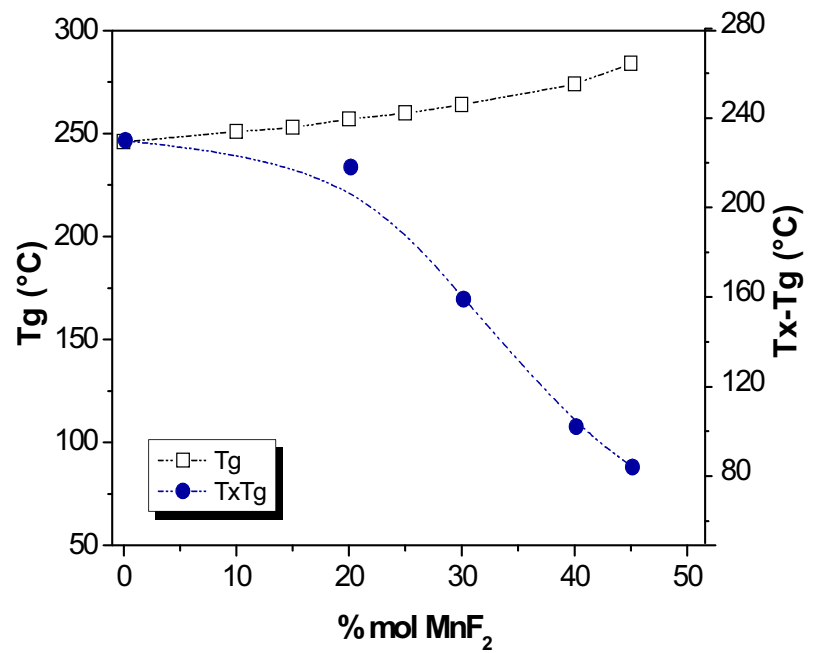

(b)

Fig. 3. Evolution of glass transition temperature $\mathrm{Tg}$ and thermal stability range $\mathrm{Tx}-\mathrm{Tg}$ versus $\mathrm{MnF}_{2}$ content: (a) $x \mathrm{MnF}_{2}-(80-\mathrm{x}) \mathrm{NaPO}_{3}-20 \mathrm{ZnF}_{2}$ and (b) $\mathrm{x} \mathrm{MnF}_{2}-(90-\mathrm{x}) \mathrm{NaPO}_{3}-10 \mathrm{ZnF}_{2}$. 


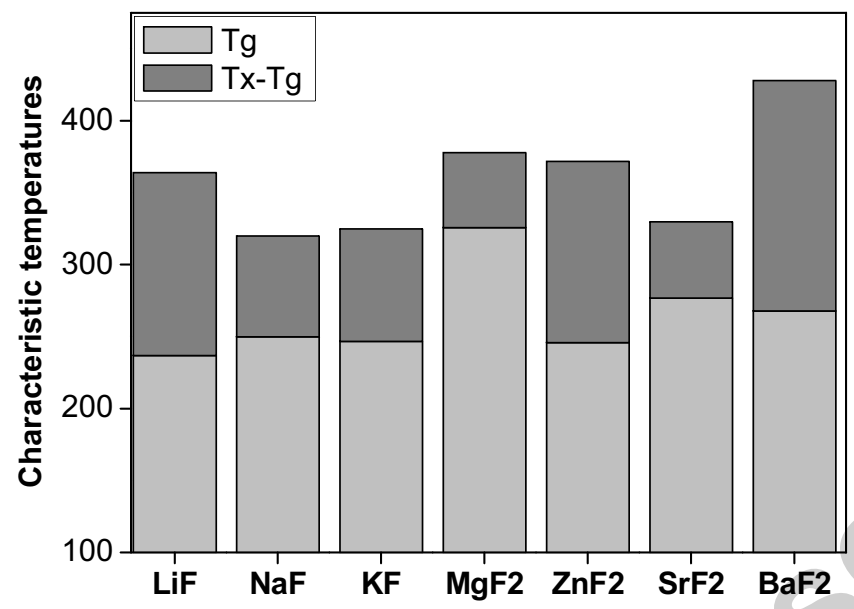

Fig. 4. $\mathrm{Tg}$ and thermal stability range of the $30 \% \mathrm{MnF}_{2}-50 \% \mathrm{NaPO}_{3}-20 \% M \mathrm{~F}_{\mathrm{n}}$ glasses $\quad(M=\mathrm{Li}, \mathrm{K}$, $\mathrm{Mg}, \mathrm{Sr}, \mathrm{Zn}$ and $\mathrm{Ba}$.)

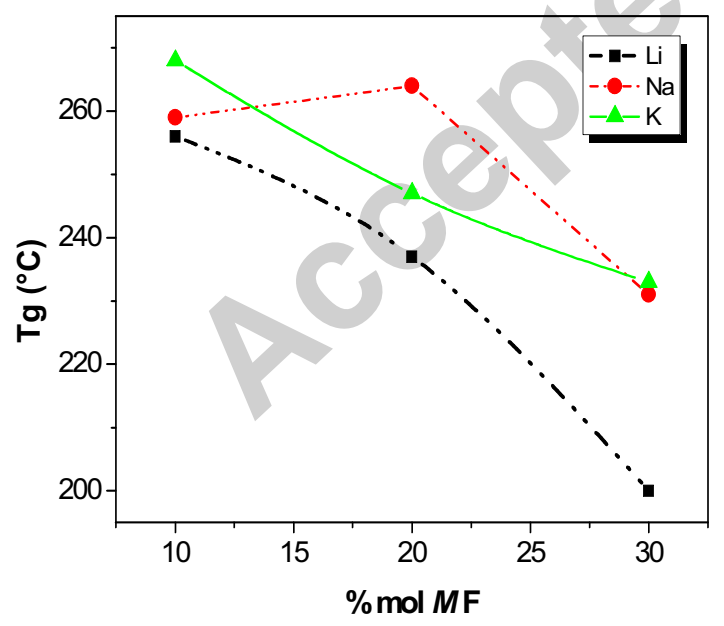

(a)

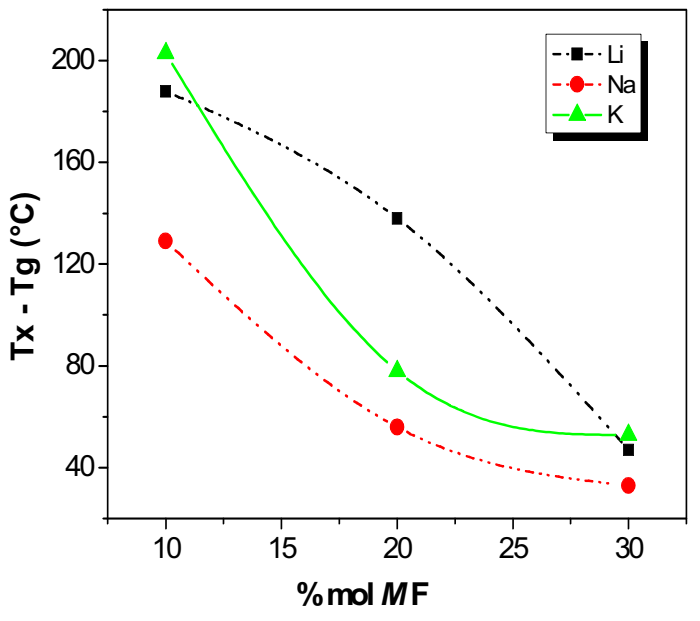

(b)

Fig. 5. Glass transition temperature $\mathrm{Tg}(\mathbf{a})$ and thermal stability range $\mathrm{Tx}-\mathrm{Tg}(\mathbf{b})$ versus alkali content in $30 \mathrm{MnF}_{2}-(70-\mathrm{x}) \mathrm{NaPO}_{3}-\mathrm{x} M \mathrm{~F}$ glasses, with $M=\mathrm{Li}$, $\mathrm{Na}$ and $\mathrm{K}$. 


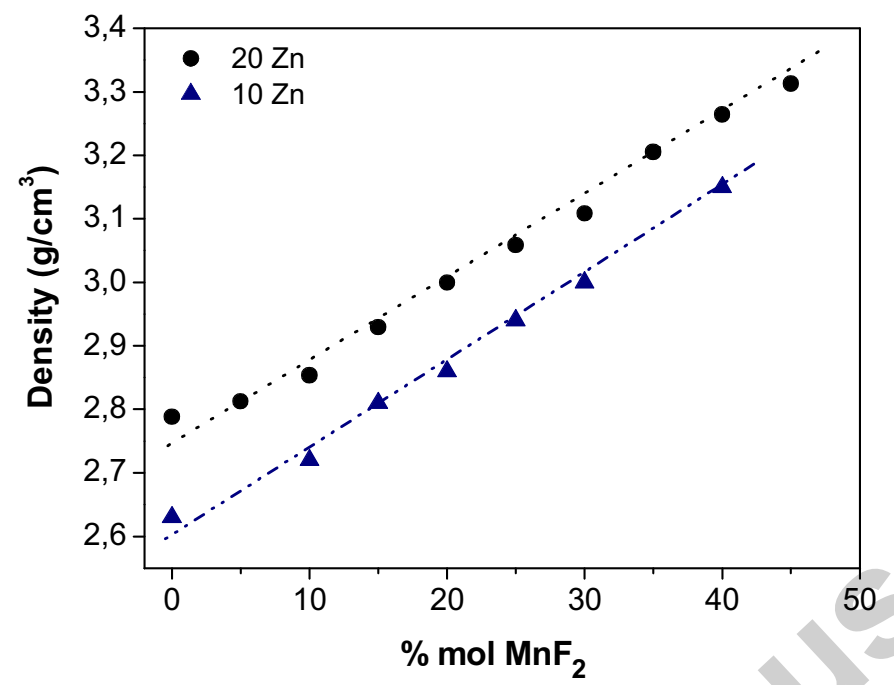

Fig. 6. Evolution of density versus $\mathrm{MnF}_{2}$ content. Glass composition :

(1) $\mathrm{xMnF}_{2}-(80-\mathrm{x}) \mathrm{NaPO}_{3}-20 \mathrm{ZnF}_{2}$ and (2) $\mathrm{xMnF}_{2}-(90-\mathrm{x}) \mathrm{NaPO}_{3}-10 \mathrm{ZnF}_{2}$

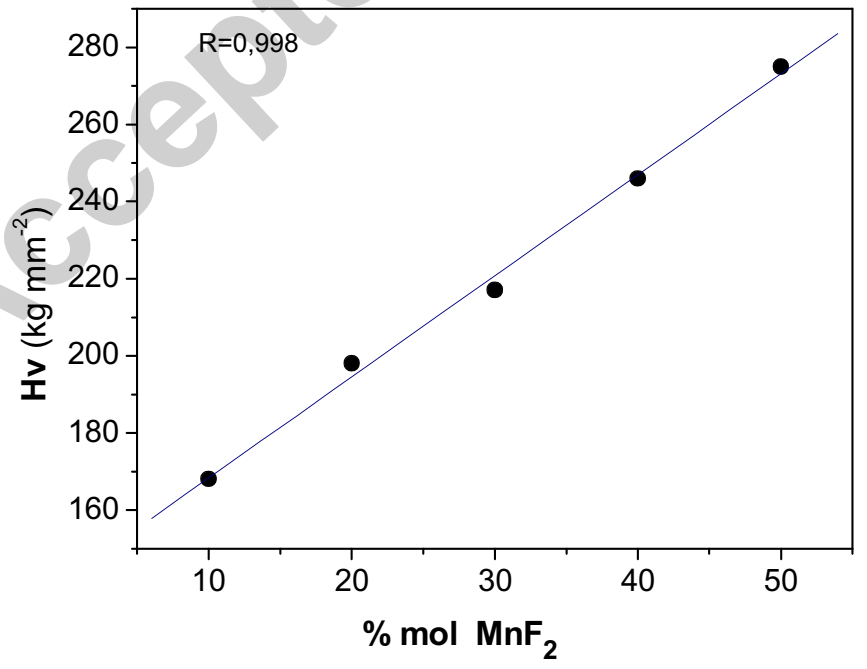

Fig. 7. Evolution of the Vickers microhardness versus $\mathrm{MnF}_{2}$ concentration in $x \mathrm{MnF}_{2}-(80-\mathrm{x}) \mathrm{NaPO}_{3}-20 \mathrm{ZnF}_{2}$ glasses. Line is drawn as a guide to the eye. 


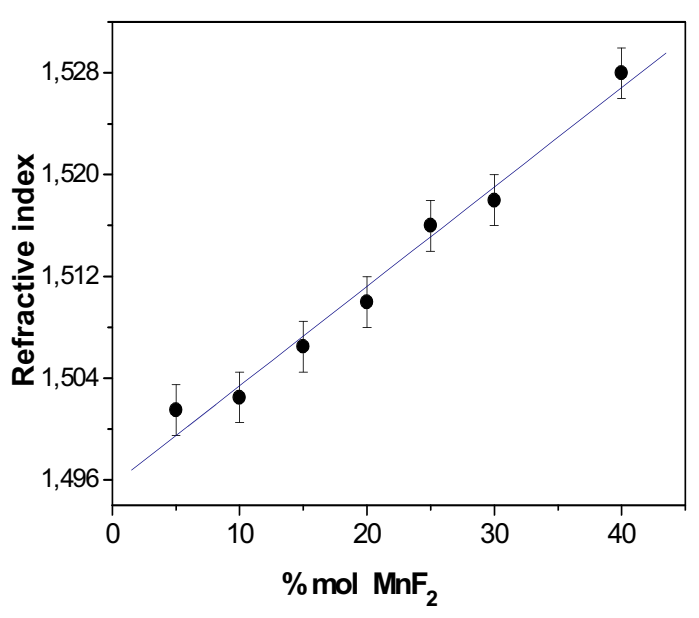

(a)

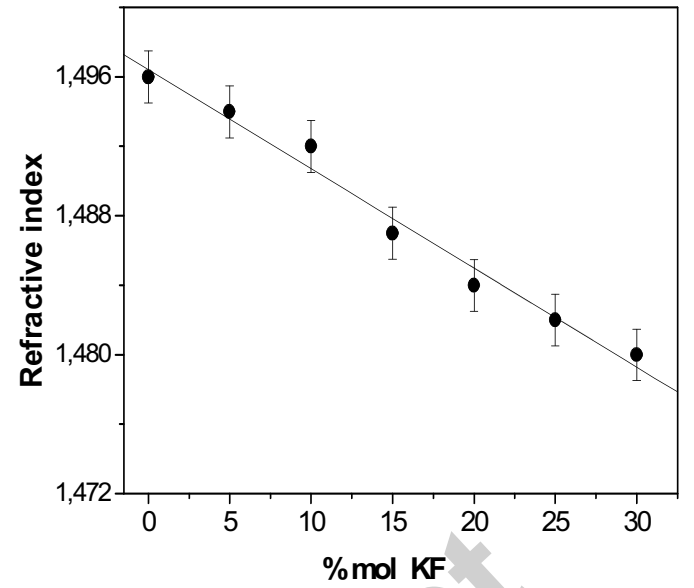

(b)

Fig. 8. Evolution of refractive index :

(a) $v s \mathrm{MnF}_{2}$ concentration in $\mathrm{x} \mathrm{MnF}_{2}-(80-\mathrm{x}) \mathrm{NaPO}_{3}-20 \mathrm{ZnF}_{2}$ system

(b) $v s \mathrm{KF}$ concentration in $30 \mathrm{MnF}_{2}-40 \mathrm{NaPO}_{3}-(30-\mathrm{x}) \mathrm{LiF}-\mathrm{x}$ KF glasses

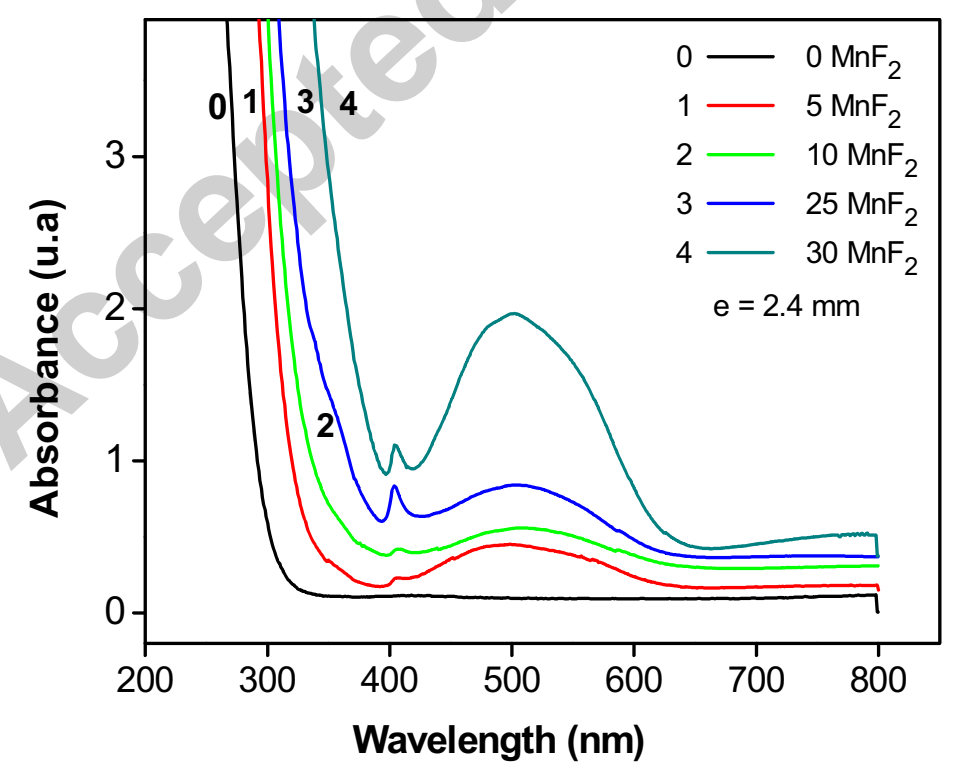

Fig. 9. UV-visible absorbance spectra of glasses in the $x \mathrm{MnF}_{2}-50 \mathrm{NaPO}_{3^{-}}(50-\mathrm{x}) \mathrm{ZnF}_{2}$ system. Sample thickness: $2.4 \mathrm{~mm}$. 


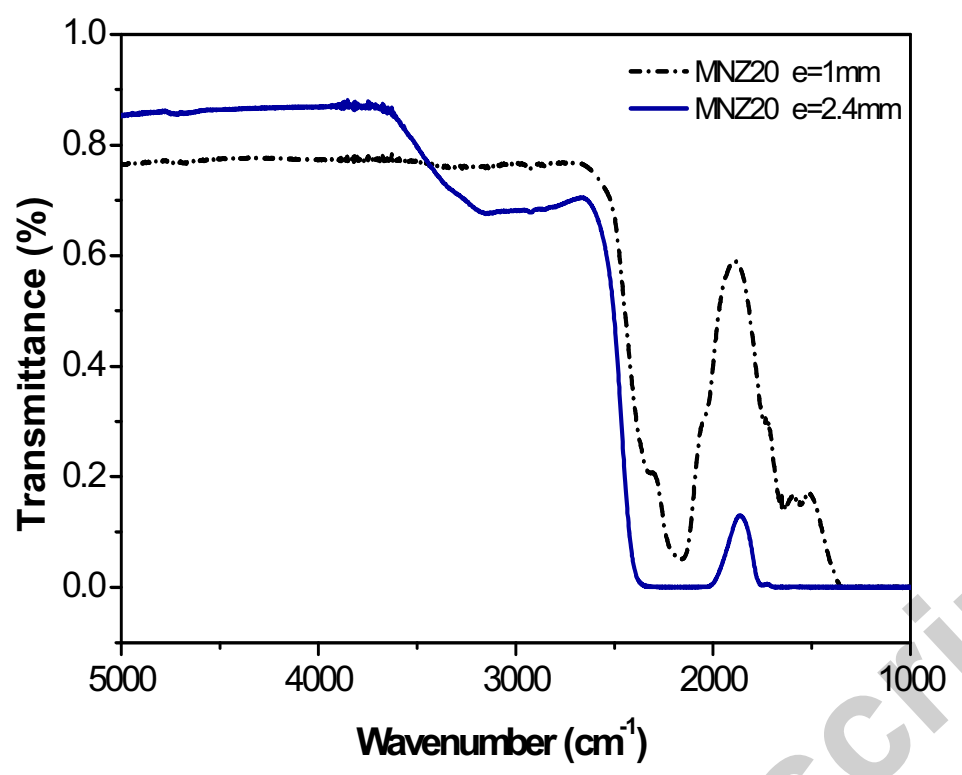

Fig. 10. IR transmittance spectra of thin $(1 \mathrm{~mm})$ and thick $(\mathrm{e}=2.4 \mathrm{~mm})$ samples of the MNZ20 glass: $30 \mathrm{MnF}_{2}-50 \mathrm{NaPO}_{3}-20 \mathrm{ZnF}_{2}$.

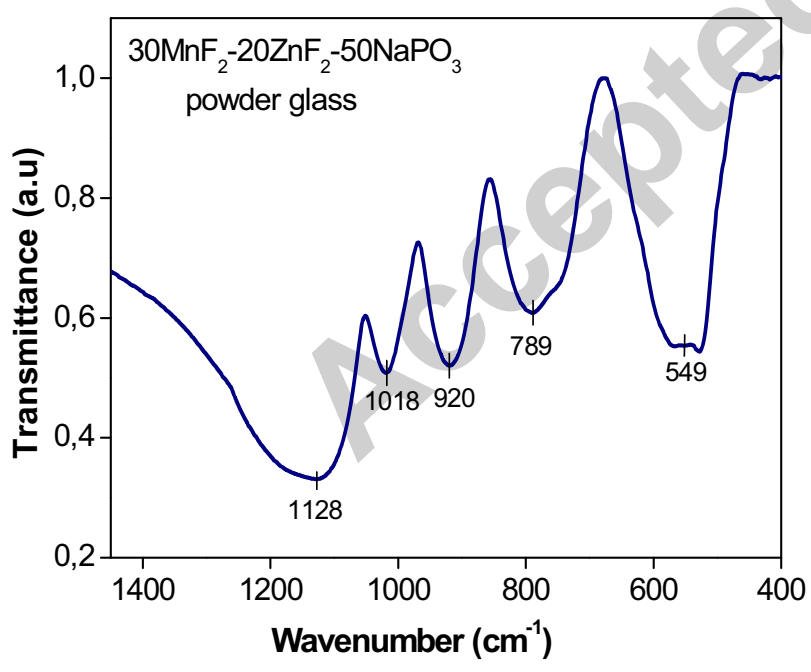

(a)

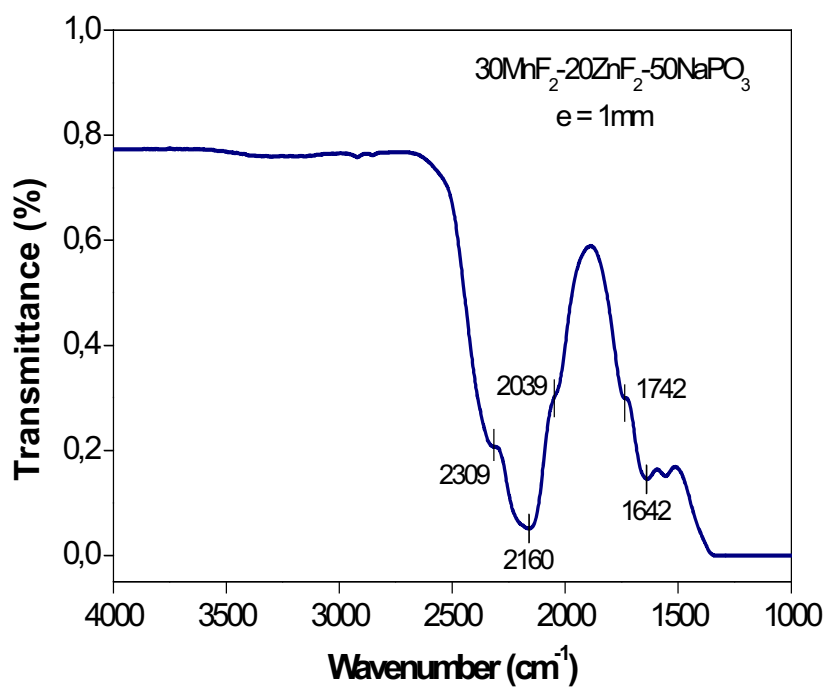

(b)

Fig. 11. IR transmittance spectra of $30 \mathrm{MnF}_{2}-50 \mathrm{NaPO}_{3}-20 \mathrm{ZnF}_{2}$ glass

(a) between 400 and $1500 \mathrm{~cm}^{-1}$, (powder dispersed in $\mathrm{KBr}$ )

(b) between 1000 and $4000 \mathrm{~cm}^{-1}$ (1mm-thick glass plate) 